\title{
Pre-Negotiation Activities: A Study of the Main Activities Undertaken by the Negotiators as Preparation for Negotiation
}

\section{Teuta Balliu}

PhD. Lecturer in the Department of Business and Administration Faculty of Economics, University of Elbasan "Aleksandër Xhuvani"

Artan Spahiu

PhD. Lecturer in the Department of Law Faculty of Economics, University of Elbasan "Aleksandër Xhuvani"

\section{Abstract}

The most part of the researches has largely been focused on what happens at the negotiation table, rather than in its preparation and planning. Through this paper we will try to underline the importance of the preparation and planning activities which are necessarily undertaken in a business negotiation. For this purpose, we have reviewed the negotiation literature regarding these pre-negotiation processes and the necessary activities for each of them. One of the most important concerns is the extent to which the negotiators follow the literature recommendations about prenegotiation processes. This is a quantitative research design which tries to collect data, through interviews and a questioner designed for it and makes analyzes and logical deductions on the results achieved. The results of this study derive from a questioner with 68 respondents, who provide an understanding of the preparation and planning activities they conduct as part of their negotiations. This study finds out that the negotiators follow the most important activities which are suggested by the negotiation literature. It is literally understandable that the preparation and planning processes precede the negotiation, which means that they are conducted generally before the meeting between the negotiating parties. In fact, even this study shows that these activities occur not only before a meeting but also after it, as the first step in preparing for the next meeting. In this regard we suggest seeing the preparation and planning not as a single event, but as cyclical processes. These findings can be used by business negotiators and by different companies.

Keywords: negotiation, preparation, planning, activities.

\section{Introduction}

People negotiate all the time; it is something that everyone does. Negotiations occur for several reasons: (1) to agree on how to share or divide a limited resource, such as land, property, or time; (2) to create something new that neither party could do on his or her own; or (3) to resolve a problem or dispute between the parties (Roy J. Lewicki; David M. Saunders; Bruce Barry, 2010). People fail to negotiate because they do not recognize that they are in a negotiation situation or because they negotiate poorly because of misunderstanding the process or not having good negotiation skills (Roy J. Lewicki; David M. Saunders; Bruce Barry, 
2010). Negotiation occurs whenever the parties cannot achieve their objectives without the help of others (Thompson, Leigh and Wang, Jiunwen and Gunia, Brian, 2010) and when they believe that a better deal can be reached by negotiating rather than by simply accepting or rejecting an offer from the other party.

Negotiation is a process of communication and the consolidation of results through agreements. It promotes cooperation through constant communication. If a substantive agreement can be reached, negotiators will implement better cooperation and maintain sustained good relations. Negotiation is a process of communicating back and forth for the purpose of reaching a joint decision (Roger Fisher and William Ury, 2011). Based on all definitions made on negotiation, it becomes clear that negotiation is essentially a process of communication, which has a specific purpose: to settle a dispute, or to reach a compromise. But, as we all know, communication is never an easy thing, even between people who have an enormous background of shared values and experience (Roger Fisher and William Ury, 2011).

The process of negotiation, defined as a collective decision-making can be described by two basic attempts: to create and to claim as much value as possible (D. Lax and J. Sebenius, 1986). Creating value describes the process of increasing the value of the negotiation subject through trade or reframing ("to expand the pie"); Claiming value means the attempt to get as much as possible of this value ("to divide the pie") (Thompson, Negotiator, 2009). The first, and often the most important step toward successful negotiation are planning and preparation. According to Thompson, about $80 \%$ of negotiators' efforts should go toward the preparation stage (Thompson, 2009). However, planning and preparation go beyond what negotiators should do before negotiation (Teucher, B.M. \& Brett, J.M. \& Gunia, Brian., 2013).

Negotiation is a dynamic communication process where new information, concerns, emotions, and goals may arise. That's why negotiators should also be prepared for dealing with contingencies as well as other factors that may interfere with goal pursuit (Teucher, B.M. \& Brett, J.M. \& Gunia, Brian., 2013).

In practice, although negotiations are very important to business activities, there is a lack of information about what actually occurs during business negotiations (R. Fells, H. Rogers, P. Prowse, U.F. Ott, 2015). We need to focus more on what negotiators should prepare before going to the negotiating table (Lewicki, R. J., Barry, B., \& Saunders, D. M., 2010). If we do not focus on preparation and planning we are going to make a lot of mistakes and will have poor outcomes. It is really important to understand what drives the behavior of the negotiators at the negotiation table. That is exactly why this paper tries to analyze the preparation and planning processes, as well as practicing them in the business activities. We also will try to understand who conducts these processes and their respective actions.

\section{Literature review}

\section{Negotiation}

There has been a dramatic growth in the international trade in terms of volume and complexity. Nowadays no one can act without interference and competition, which came from all over the world. The globalization has changed the basic requirements of doing business. In this point of view the negotiation is a field of interest.

Negotiation is an interpersonal decision-making process necessary whenever we cannot achieve our objectives single-handedly. Negotiations include one-on-one business meetings, but also multiparty, multi-company, multinational relationships, and the public sector. 
Whether simple or complex, negotiations boil down to people, communication, and influence. Even the most complex of business deals can be analyzed as a system of one-on-one relationships (L.Thompson, 2012). Simona Sliogeriene begins her course handbook "Negotiation and Business Ethics" by saying that: when you hear the word negotiation, you know there are two sides and they're willing to talk to each other (Sliogeriene, 2015).

\section{Negotiation framework}

Negotiation framework defines the problem or opportunity, which involves eliminating irrelevant clutter. If a negotiator wants to make a proposal or consider an offer, he considers only the applicable positive and negative effects. By organizing the information so he/she can sharpen his/her understanding of what's on the table. A framework allows the negotiator to interpret important information through analysis. A frame focuses on problems, issues, interests and solutions. It enables senior managers and executives to decide what the substantive issues would be in critical negotiations and start to develop some workable scenarios. It should focus the team on the results; this means that as a leader the manager needs to measure a range of possible outcomes, not just the money.

Every negotiation is different and having a practical and successful framework allows the manager to focus on his/her preparation. From the literature of the negotiation as a negotiation framework, we can be focused in the model of Ghauri in 2003, as one of the latest model in this field. This model has three groups of variables; background factors, process and atmosphere (Pervez N. Ghauri and Jean-Claude Usunier, 2003). As we can notice in the figure below the pre-negotiation is one of the three stages of negotiation. A stage of the process refers to a specific part of the process and includes all actions and communications by any party pertaining to negotiations made during that part.

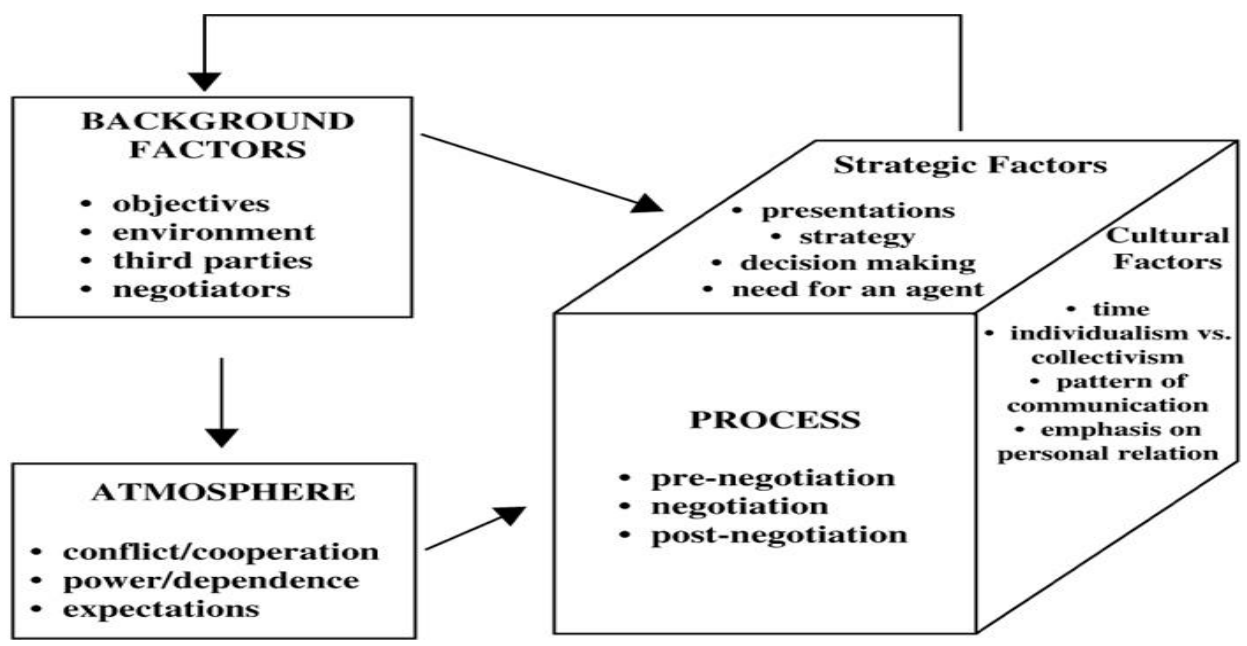

Figure 9: Ghauri model of the negotiation framework

\section{Pre-negotiation process}

Negotiation strategy formulation is necessary for access to the negotiating context. In the negotiations between the entities even within the same country or region, preparation can be 
really complicated. Nowadays the parties are more involved in complex negotiations than in just local negotiations. In practice there are a lot of obstacles. Although there is an extensive research literature into the practice of negotiation itself there is a limited peer-reviewed literature covering empirically grounded research into the practice of preparation and planning activities. In our country it is really difficult to find researches in negotiation or in preparation and planning activities.

As we mentioned, negotiation is a process of decision making by which people, who have conflicting interests, determine how they are going to allocate resources, or work together in the future. Interests are the concerns, needs, fears or desires underlying negotiators' conflicting positions (Roger Fisher and William Ury, 2011). The three negotiation stages are: 1) pre-negotiation, 2) active negotiation (face to face negotiation) and 3) post-negotiation, meaning implementation and follow-up issues. This paper has in focus the stage of prenegotiation, which steps (or phases) are shown in figure 2 .

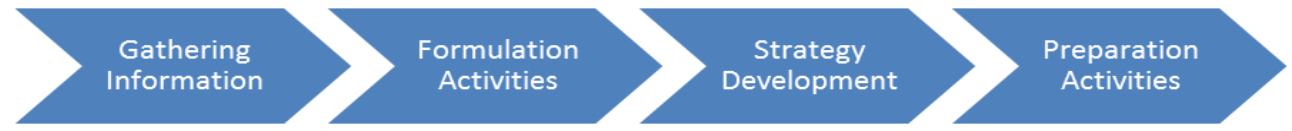

Figure 10. The steps of pre-negotiation

Generally all the academic text book literatures agree that being prepared to negotiate requires a set of activities which are typically divided into three or four steps.

The first step or component in the framework, "Information Gathering", focuses on environmental factors and on information collection from the other party, including research into their organization and learning about their style and personality. The second step, "Formulation Activities", concerns planning activities which involves objectives, interests, the assessment of the best alternative to a negotiated agreement etc. The third and the fourth component, "Strategy Development" and "Preparation Activities" respectively, concern planning activities involving the development of a plan (strategy) to reach the goals outlined, the development and preparation of the customer presentation in addition to addressing the logistical concerns.

The study of Peterson and Shepherd has contributed on exploring the activities that negotiators perform when preparing for a negotiation meeting within a business-to-business sales negotiation (Robert M. Peterson, C. David Shepherd, 2010). According to them, prenegotiation planning activities are:

a. Information Gathering Activities; the act of collecting, processing, analyzing and evaluating available data concerning the other party and relevant environmental factors.

Collect primary data (consult with others in your firm, client's firm, $3^{\text {rd }}$ party firms);

Collect secondary data (industry, government, trade publications, internet, annual reports, etc.);

Gather data on market conditions, future trends, and how they may affect each party; 
Understand other party (general profile, personality profiles, and communication patterns of others involved);

Knowledge of the competitive alternatives the client may be pursuing;

Review history of the relationship form internal sources/data;

Review the previous strategies used by both you and the client;

Knowledge of client's anticipated preparation;

Understand the other's decision-making unit (structure and process);

b. Formulation Activities; involves developing goals, specific objectives and setting the parameters for each issue to be negotiated.

Set negotiation objectives;

Define your interests;

Define issues to be deliberated;

Define the mix dealing (what is on the table and what is not);

Set limit levels on issue(s) (optimistic, realistic, pessimistic);

Contrive BATNA (Best Alternative to a Negotiated Agreement), point where you agree not to do business;

Create an agenda for negotiation;

Incorporate potential plans of the other party;

Create a negotiating team (assign responsibilities, role, and deadlines);

Outline the role you will assume (if part of a team);

Consult with others regarding your plan/strategy;

c. Strategy Development Activities; strategy is a plan that integrates a person's goals and action sequences into a cohesive whole.

Develop team strategy (who will speak, who will introduce demands, concessions, solutions);

Develop trade-off strategy on the issues (what you will give for what in return);

Develop collaborative strategies (cooperative ideas and options);

Develop competitive attacking strategies (options to be highly aggressive);

Develop competitive defending strategies (options to defend against attacks);

Develop concession strategy (slow, but planned concessions to pacify client);

Develop strategy/ies that use a 3rd party to influence client actions (friendly/strong influence asserted from 3rd party);

d. Preparation Activities; involves rehearsing verbal communication, arranging/creating support materials and attending to logistical concerns. 
Role Play;

Script opening ceremonies (formal opening statement);

Prepare questions from client (questions that are in need of answers);

Prepare for anticipated questions from client (answers to questions or objections);

Prepare a mutual interest business topic (topic both parties find relevant to business concerns);

Prepare visual and other aids (charts, graphs, presentation aids);

Logistical concerns (seating arrangements, food, drink, room availability);

\section{Research methodology}

Lewicki (2010), Peterson and Shepherd (2010), and other sources have made the observation that despite the extensive research into negotiation, few have focused on what is actually prepared in anticipation of negotiations. (Lewicki, R. J., Barry, B., \& Saunders, D. M., 2010) Even in our country there are very few studies regarding the preliminary issues on which the negotiators are prepared before entering into negotiations.

This paper tries to examine the preparation practices of a group of commercial negotiators with the aim to understand how they prepare for their negotiations. The purpose of this study is to explore the activities that individuals undertake in preparation for a sales-oriented negotiation situation. The objective of the research is to analyze what negotiators do before going to the negotiation table in order to obtain the best outcomes. Our research questions are: Which preparation activities are undertaken to perform a business negotiation? When are taken this preparation and planning activities?

First we have tried to identify a comprehensive list of activities which are often used in preparing for a business negotiation. The literature review served to identify and categorize around 34 activities, which were recommended as part of the preparation process. This list of activities was first discussed with students at MBA program in our faculty. In this way we can have better results in our attempt to develop the theory. Than we have used a scenario, a version of Graham's Bolter Simulation (1984) which is widely used in negotiation researches now days (you can find it in the appendix).

After reading the scenario all the participants have more possibilities to think about the activities which are performed before going to the negotiation table. An open-ended questionnaire, with 68 purposefully selected respondents, provided an understanding of the preparation and planning activities they realize as part of their ordinary customer negotiations. The practitioners were all employed by different companies in the private sector and them all negotiated contracts with a customer (typically a private or public entity). A prenegotiated activity will be counted as being commonly conducted only if $15 \%$ or more respondents have reported this activity as having been conducted.

\section{Data analyses and finding from the research}

\section{III.1. Information gathering activities.}

In this section we will try to present data on activities cited as having been conducted, that is, those activities that the respondents said they undertook in preparation for a sales-oriented 
negotiation situation. The questionnaire was distributed to 80 negotiators, resulting in 68 usable responses. The respondents were predominantly male $45 / 23$, mostly under 45 years old, and had an average of 3-5 years of professional experience. The findings have been summarized in the tables below and 23 of the 34 categories were commonly conducted.

It has been found that negotiators' preparation is generally consistent with the prescriptions in the literature but there are some activities, included in our questionnaire, that negotiators do not do while others are conducted less often than expected. Furthermore, negotiators often conducted activities from their own perspective, rather than from the other side's perspective, and more negotiators collect primary data rather than secondary data.

The argument underlined from the literature was that consulting the trade publications and annual reports, with subject within the field of negotiation, is the best way to collect secondary data. But, business negotiators in the company usually work within the same industry and are expected to be familiar with it and, therefore, do not need to make any specific preparations in that respect. Supporting this theory, regarding our research, there are only five respondents whose mentioned annual reports and trade publications in the entire study.

A deeper look into the comments confirms that, with few exceptions, the negotiators of the small companies negotiate in their own country of citizenship or in a country in which they have a deep understanding. On the other hand, the buyers are becoming more globalized and the use of globally diverse negotiation teams is becoming more common. These may justify extra attention to other party issues by the seller. Similarly, the complex business negotiations which are conducted by smaller companies, which may not have negotiators with large experience, would do better to dedicate some extra time to this part of preparation.

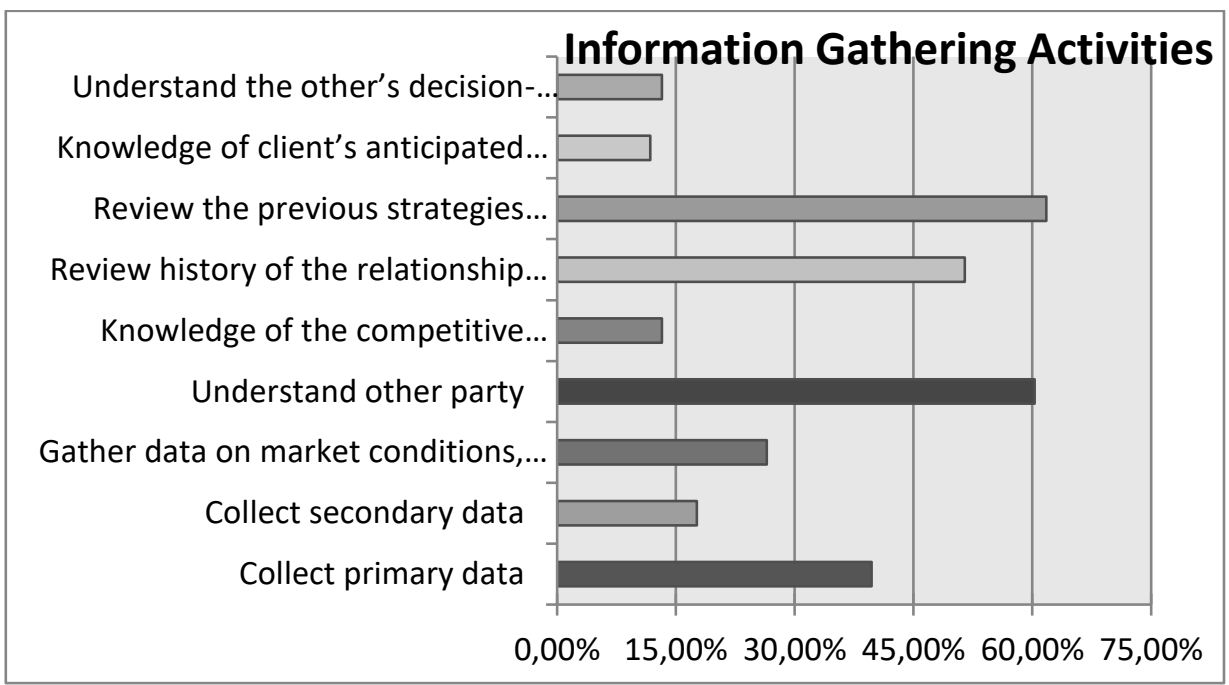

Graph 1: Information gathering activities

\section{III.2. Formulation activities.}

Under this category, we find that more respondents consider the customer's position rather than their own position. While the interest in understanding the other side is understandable, it may still be confounding that fewer people report on their own positions. A plausible reason, 
behind the high number of concerns for the other party's positions compared to their own, may simply be that these negotiators are deal makers who are constantly engaged in making similar deals and their own priorities have become implicit to them.

Regarding the goal setting category, none of the respondents referred to how the setting or development of the goal should take place. This omission may be an indication that in several cases the negotiators do not set goals as a team. One explanation for the absence of goal setting may be that negotiators consider the goal to be a given one by confusing it with the mandate given by management which may induce a lower outcome for the seller. A second explanation might be that negotiators see little reason to engage in this type of planning, as they often overestimate their ability to achieve their goals.

Within the category of goal setting, once again we find that respondents are mainly selfconcerned. The low number of responses to priorities in general, and to the priorities of the other side specifically suggest that negotiators are not adequately prepared to take advantage upon the differences and are, thereby, possibly entering into suboptimal agreements. This finding confirms the claims made by various scholars that negotiators consistently leave money at the table.

Contrive BATNA were found to be the second largest category in this theme and in the whole data-set with 42 (67\%) respondents. The high number is not surprising considering the importance of understanding the point where negotiators agree not to do business.

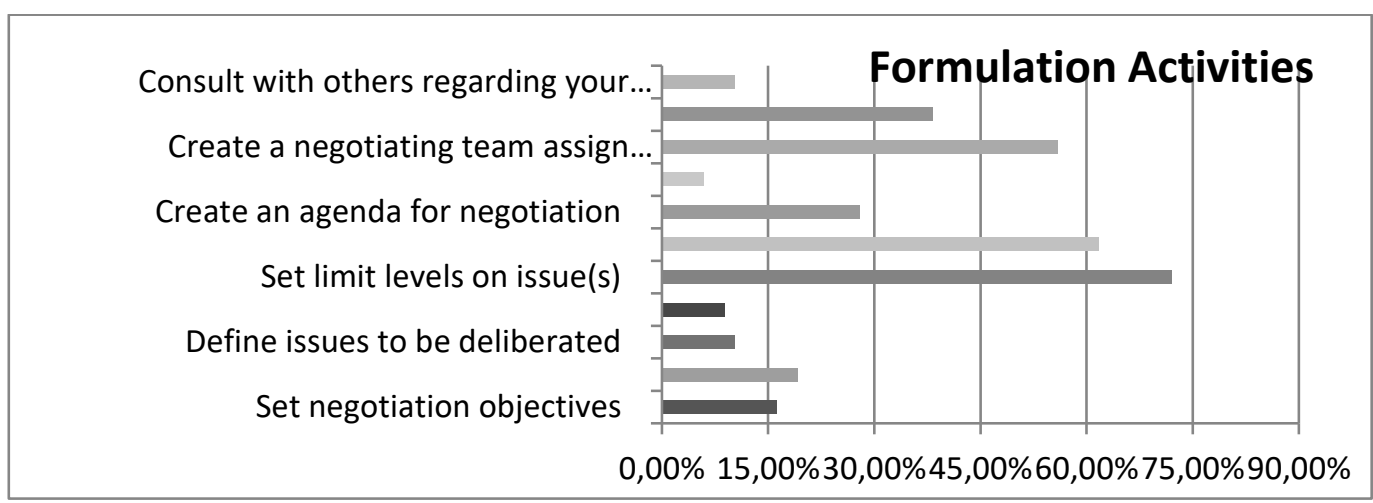

Graph 2: Formulation activities

Within this category, one more time, we observed not so much attention to the other part and to their plans.

\section{III.3. Strategy Development Activities.}

As we can notice in the table below, a large number of responders underlined the importance of the strategy to use a third part to influence client actions ( 41 from 68). The results show also that collaborative strategies were mentioned only by eight respondents out of 68 respondents. This strategy is known as "constructive", "ethical" or "interest-based" strategy and is treated as an important and valuable element, while seeking an equitable and fair 
agreement. One goal of collaborative negotiation is keeping the relationship intact because the parties may want to continue to do business together.

Understanding the other side interests, motivation, and value is the key of reaching a win-win solution and if negotiators tend not to be focused on the other part side, during the preparation and planning activities, than they do not pay the right attention to the collaborative strategies. The reason for this low number of respondents may be attributed to procedural precedent in which negotiators simply follow the normal process, used when they negotiate similar deals, or it is because of their low experience in the negotiation field.

We observed also not much attention to the concessions. The reason for the apparent lack of attention to developing a concession plan, prior to the customer meeting, may simply be that the negotiators do not get this far into the preparation with their busy schedules. Another reason may be that the time required to conduct this complex activity is not considered valuable, compared to other more pressing possible activities. Overconfidence may again partly explain why negotiators do not engage in this activity.

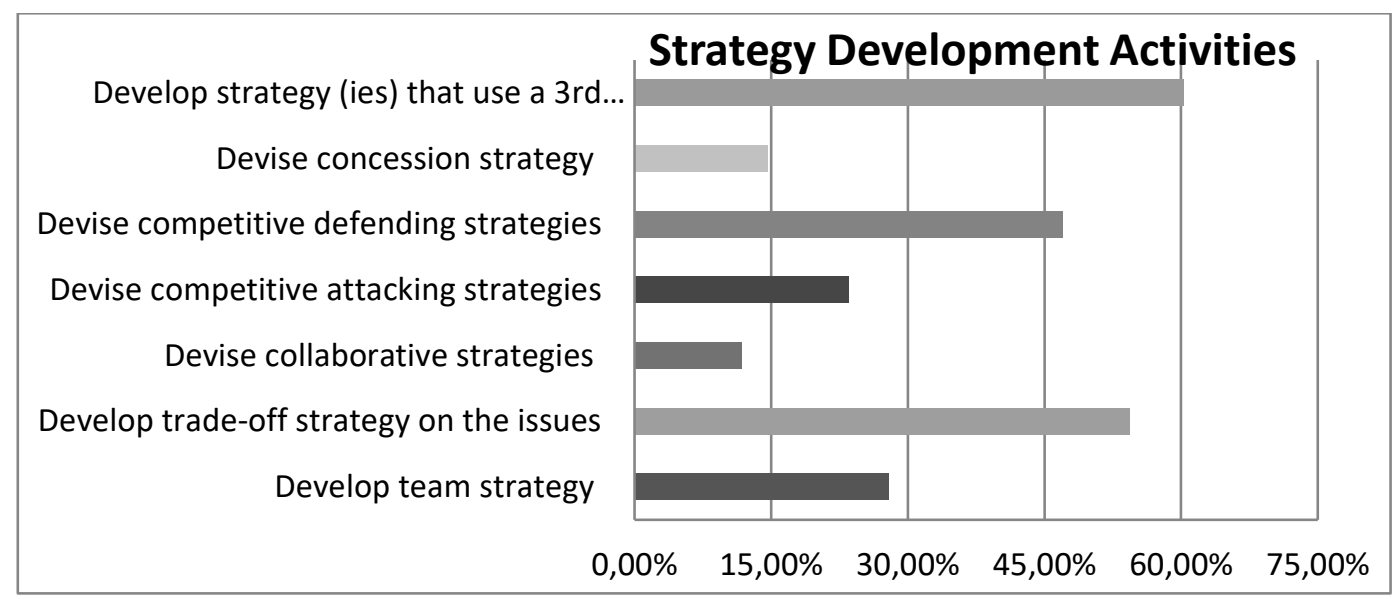

Graph 3: Strategy development activities

\section{III.4. Preparation Activities.}

Although how to negotiate and what to negotiate enjoys full support from the authors selected from the literature review, other researchers such as Kolb and Williams (2001) have found evidence to suggest that executives ignore aspects concerning how and what to negotiate as a way to achieve the goals of the negotiation. As we can notice in the table 4, the preparation of the visual and other aids and role plays are activities not used in the preparation phase of a negotiation. The reason for this low number of respondents may be attributed to procedural precedent in which negotiators simply follow the normal process, used when they negotiate similar deals and maybe even with the same customers.

Research has found that testing the assumptions made about the other party's interests, priorities and other issues will facilitate the discovery of integrative agreements. Testing is typically achieved through the use of questions (one should expect negotiators to prepare which questions to ask when entering into the negotiation with the customer). Still, only six survey participants planned to ask questions. One explanation may be that negotiators 
consider their assumptions, made earlier in the preparation as being valid and complete, possibly as a result of the overconfidence, and see no need to prepare questions in order to test these. Another related explanation may be that negotiators simply do not consider this part of preparation, even though they ask questions during the customer negotiation. Whatever the reasons, we suggest that negotiators should consider preparing questions.

The logistical and openings ceremonies are the most mention activities in this theme.

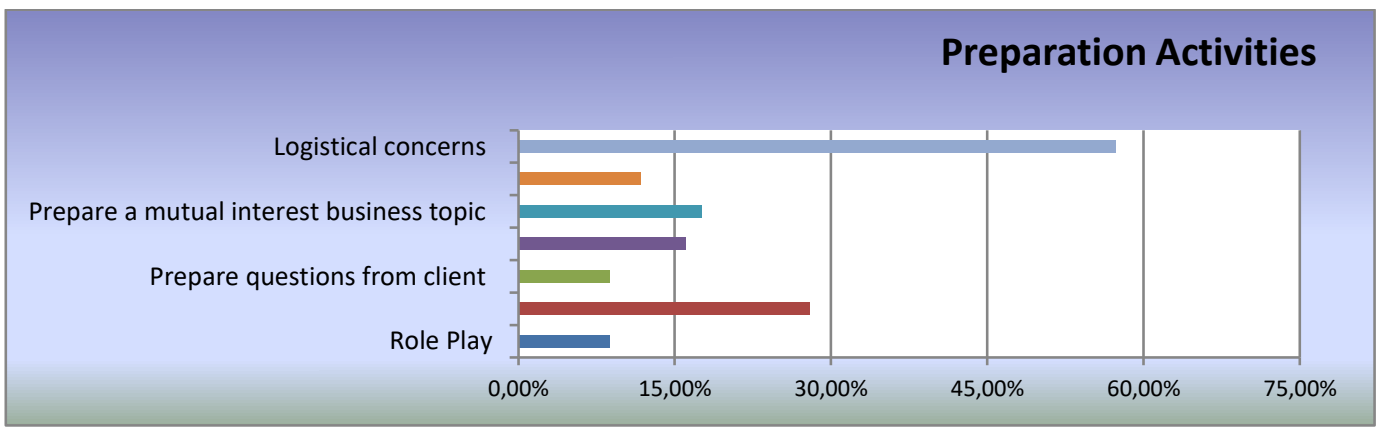

Graph 4: Preparation activities

\section{Conclusions and recommendation}

Negotiation preparation and planning has always been regarded as important and the advice concerning how to prepare is extensive. The comparison between advice and practice has revealed that, although the principles which have been recommended are usually followed, some apparently important aspects are not. This study is drawn on practitioner data to examine how negotiators prepare and plan for business negotiations and, in particular, has examined the extent to which they follow the prescriptions given in academic literature. The findings have practical implications not only for the company from which the data were collected but, more importantly, for other companies and negotiators involved in negotiating business deals.

Summarizing the findings, 23 of the 34 recommended planning and preparation activities were found to be conducted. Negotiators often conduct formulation activities from their own perspective, rather than from the other side's perspective, and more negotiators collect primary data rather than secondary data. Now days the buyers are becoming more globalized and the use of globally diverse negotiation teams is becoming more common, which may justify extra attention to other part issues by the seller. Similarly, other complex business negotiations which are conducted by smaller companies, but which may not have negotiators who are well versed in the annual reports contexts, would do well to dedicate some extra time to this part of planning and preparation.

Regarding the formulation activities we can say that 7 of 11 activities are conducted. In this way, the negotiators are paying more attention to the setting limits levels on different issues. Due to the relationship between setting goals and outcomes in negotiations, the goal setting category was expected not only to support the proposition but also to yield many respondents, which were not the case compared to the larger categories in this theme and in the dataset as a whole. Moreover, none of the respondents referred to how the setting or development of the 
goal should take place. This omission may be an indication that in several cases the negotiators do not set goals as a team.

We also observed not much attention to the concessions. The reason for the apparent lack of attention in developing a concession plan, prior to the customer meeting, may simply be that the negotiators do not get this far into the preparation with their busy schedules.

Although one of the most important activities, part of the preparation activities, are the questions, we noticed that only six survey participants planned to ask questions. Recent researches suggest that testing the assumptions, made about the other party's interests, will facilitate the discovery of integrative agreements, which is typically achieved through the use of questions. Whatever the reason of the low number of participants planning to ask questions, in our survey, we strongly recommend to prepare questions before going to the negotiation table.

By developing a comprehensive and clearly structured checklist of preparation activities, this study has provided a framework for further research into the practices of negotiators. The checklist provides structure for the analysis of the broad aspects of preparation activities in negotiation. Moreover, the checklist helps on detailed investigation of particular preparation tasks, such as the way in which negotiators develop their interest and goals.

\section{Bibliography}

[1] Backhaus, Klaus \& Van Doorn, Jenny \& Wilken, Robert. (November 2008). the Impact of Team Characteristics on the Course and Outcome of Intergroup Price Negotiations. Journal of Businesses- to- Business Markering, 365-396.

[2] D. Lax and J. Sebenius. (1986). the Manager as Negotiator. New York.

[3] Lewicki, R. J., Barry, B., \& Saunders, D. M. (2010). Negotiation. Boston: Mcgrawhill/Irwin.

[4] Negotiation and Business Ethics (2015). Klaipeda

[5] Negotiation Theory and Strategy (2009). New York: Aspen Publishers, Inc.

[6] Negotiator (2009) Ed. São Paulo Pearson Prentice Hall

[7] Pervez N.Ghauri and Jean-Claude Usunier (2003), International Business Negotiation Oxford, UKELSEVIER Ltd.

[8] R.Fells, H.Rogers, P.Prowse, U.F. Ott (2015) Unraveling Business Negotiations Using Practitioner Data, Negotation and Conflivt Management Research, 119-136

[9] Robert M.Peterson, C.David Shepherd (2010) Preparing to Negotiate: An Exploratory Analysis of the Activities Comprising the Pre-Negotiation Process in a Buyer-Seller Interaction, Marketing Management Journal, 6675

[10] Roger Fisher and William Ury (2011), Getting to Yes: Negotiating Agreement Without Giving in, Random House Business Books

[11] Roy J. Lewicki; David M. Saunders; Bruce Barry (2010), Negotiation, Mcgraw-Hill

[12] Teucher, B.M. \& Brett, J.M. \& Gunia, Brian. (2013), Negotiation the Mind and Heart of the Negotiator (2012), New Jersey Pearson Education, Inc.

[13] Thompson, Leigh and Wang, Jiunwen and Gunia, Brian (2010), Negotiation. Annual Review of Psychology, 491-515 


\section{Appendix a}

\section{The Bolter Scenario}

You are the lead sales representative in a contract negotiation between two firms over the sale of a complex compressor system used in the offshore production of natural gas. Stated simply, the compressor forces the natural gas from the seabed into a system that allows for its capture. The two involved firms are: 1) Bolter Turbines Inc.- - manufacturer of natural gas production equipment (with whom you are a salesperson), and 2) Maverick Natural Gas Inc.-a producer of natural gas with production operations concentrated in the Gulf of Mexico. This contract negotiation is based on the potential purchase by Maverick of one compressor system, but there is always a desire of selling additional units. Maverick has been a customer for several years and knows you and your company through previous work you have performed for them. This compressor system would represent a lucrative increase in business from your client, and would be one of the first sales for a new and improved compressor system. The sales process has proceeded relatively smoothly, a few bumps here and there, but now the big decisions must be made during the negotiation. Over the past few months, you (the Bolter sales representative) have been actively involved in preliminary sales negotiations with the Maverick purchasing agent and other Maverick staff members over the purchase of the system. This product is a specialized compressor system recently developed by your firm, and is rated as the best in the market at extracting natural gas. You have offered Maverick a general price range for the system ( $\$ 2-3$ million), but have not talked any specifics yet. Your role in the negotiation will be to negotiate with the other party to reach a decision on a contract for the system, including finalizing the price on the compressor, the price of the service contract, and the delivery date. Again, your task is to complete the negotiations and get a signed agreement for the 1) compressor system, 2) service contract, and 3) delivery date of the equipment. 